\title{
Effect of early and delay starting of enteral feeding in post-pancreaticoduodenectomy patients
}

\author{
Bidhan C. Das, Mozammel Haque, Mohammad Saief Uddin, Md. Nur-E-Elahi, \\ and Zulfiqur Rahman Khan
}

\author{
Department of Hepatobiliary, Pancreatic \& Liver Transplant Surgery, \\ Bangabandhu Sheikh Mujib Medical University, Dhaka, Bangladesh
}

\begin{abstract}
Backgrounds/Aims: This study was undertaken to see the effect of early starting of enteral feeding after pancreatoduodenectomy (PD). The results were compared with existing nutritional practice in which enteral feeding started, usually after 7 to 8 postoperative day (PODs) in our institute. Methods: Thirty patients whome underwent a PD from January 2016 to December 2016 were included in the study. They were divided into two groups, I and II. In group I $(n=15)$, enteral feeding was started from the $2^{\text {nd }}$ POD through the nasojejunal feeding tube along with parenteral partial nutrition support. In group II $(n=15)$, no enteral feeding was given up to seventh and eighth PODs, except the perenteral feeding. Post-operatively, serum albumin levels, total lymphocyte count, total bilirubin levels, serum alkaline phosphate levels were measured for two weeks postoperatively in all the patients for assessing nutritional, immunological and cholestasis status. The mortality, morbidity and lengths of post-operative hospital stay were also recorded. Results: Postoperatively, the serum albumin level and lymphocyte count decreased from the pre-operative level on the third POD and it gradually increased from the seventh POD onwards in both groups. However, they remained persistently higher in group I than group II. The total bilirubin and alkaline phosphatase decreased to normal levels within the seventh POD in Group I. However, they remained higher than normal levels on POD 14 in Group II. The morbidity and hospital stay was significantly lower in group I than group II. Conclusions: Early enteral feeding should be considered after PD. This is because it will improve nutritional, immunological status and cholestasis. Therefore, it reduces morbidity and shortens the hospital stay. (Ann Hepatobiliary Pancreat Surg 2019;23:56-60)
\end{abstract}

Key Words: Early and delay; Enteral feeding; Pancreatoduodenectomy

\section{INTRODUCTION}

The maintenance of proper nutrition after pancreaticoduodenectomy (PD) is a great challenge. Patients could not take food properly before surgery because of jaundice and malignancy. It is a very stressful surgery because the procedure needs wide dissection and multiple reconstructions, which cause the delayed starting of proper nutrition. These factors produce severe nutritional deficiency in the patients, which may be the one cause of high postoperative morbidity. ${ }^{1}$ Poor nutrition provides unfavorable outcomes after surgery, increases infection rate, ${ }^{2}$ causes poor healing of wounds, ${ }^{3}$ and anastomotic failure. ${ }^{4}$ Therefore, special attention on post-operative nutritional management after
PD is essential. There are very few published clinical information $^{5-9}$ focusing on the postoperative feeding after PD. Clinical practices on post-operative nutrition support after PD vary from center to center. It includes partial parenteral nutrition, ${ }^{6}$ total parenteral nutrition, ${ }^{6}$ enteral feeding through jejunostomy tube ${ }^{7}$ or nasojejunal tube ${ }^{8}$ or a combination of both the enteral and parenteral feeding. ${ }^{8,9}$ The time of giving enteral feeding after PD is also different from center to center. Some authors feel comfort to start early enteral feeding. Others prefer to start in delay enteral feeding after PD. There is no standard nutritional method after PD that is yet to be developed. The current practice nutrition support after PD in our institute involves the giving of parenteral nutrition in the early post-oper-

Received: May 31, 2018; Revised: August 5, 2018; Accepted: August 18, 2018

Corresponding author: Bidhan C. Das

Department of Hepatobiliary, Pancreatic \& Liver Transplant Surgery, Bangabandhu Shiekh Mujib Medical University, Room no-616, $5^{\text {th }}$ Floor, Block-C, Shahbag, Dhaka 1000, Bangladesh

Tel: +88-02-55165820, Fax: +88-02-55165797, E-mail: dbidhan@yahoo.com

Copyright (C) 2019 by The Korean Association of Hepato-Biliary-Pancreatic Surgery

This is an Open Access article distributed under the terms of the Creative Commons Attribution Non-Commercial License (http://creativecommons.org/ licenses/by-nc/4.0) which permits unrestricted non-commercial use, distribution, and reproduction in any medium, provided the original work is properly cited. Annals of Hepato-Biliary-Pancreatic Surgery • pISSN: 2508-5778 - elSSN: 2508-5859 
ative period, and enteral feeding is usually started at 7 to 8 POD. This study was undertaken to see the effect of early starting of enteral feeding after PD. The result was then compared with existing nutritional practice in our institute. The study may help to develop a nutrition management protocol after PD.

\section{MATERIALS AND METHODS}

This is a case-controlled prospective study. The study include patients $(n=30)$ that underwent pancreatoduodenectomy surgery in different units of the Department of Surgery of Bangabandhu Sheikh Mujib Medical University, Dhaka from January 2016 to December 2016. All patients were evaluated thoroughly before surgery. Anemia, coagulopathy, dehydration and hypoalbuminia were corrected. Appropriate antibiotics were applied before the surgery when required. Informed consent was taken for operation after proper counseling.

Patients were divided in two groups, I and II. In group I $(n=15)$, the patients a nasojejunal (NJ) feeding tube was placed peroperatively for starting postoperative early enteral feeding. Enteral feeding was started from the second post-operative day (POD). Drinking water, ORS (Oral ReHyDraTion Salts), green coconut water $(30 \mathrm{ml} /$ hour, 10 feeds) through a NJ tube, which was gradually increased (50-200 ml/hour, 10 feeds) in the subsequent PODs (clear soup, dal water, rice water, formulated milk etc). Parenteral nutrition support in the form of $25 \%$ glucose saline (500 $\mathrm{ml}$ daily), an amino acids and fatty acid solution $(500 \mathrm{ml}$ every alternate day), normal saline $(1000 \mathrm{ml})$ with potassium (40-60 mmol) with vitamin B and $\mathrm{C}$, was also started from the second POD. The amount of fluid and calorie was adjusted according to the standard fluid (30-40 ml/ $\mathrm{kag} /$ day), electrolytes and energy requirement $(30-40 \mathrm{kca} /$ $\mathrm{kg}$ /day). The NJ tube was removed from the seventh and eighth PODs, and normal diet was started by mouth. The patients that developed abdominal cramps and diarrhea after starting the formula food orally were excluded from the study. In group II $(n=15)$, the patients that received ongoing nutritional management practice after pancreatectomy were included in this group. In these patients, nasogastric (NG) tube were placed preoperatively for the decompression of stomach. No enteral feeding was given up to the seventh and eighth PODs. Parenteral feeding (as describe in Group I) was given during the initial seventh and eighth PODs. The NG tube was removed from the seventh and eighth POD, and normal diet was started by mouth.

Patient's pre-, per- and post-operative data were recorded on a record file. Post-operatively, the serum albumin levels, total lymphocyte count, total bilirubin levels and serum alkaline phosphate levels were measured on PODs 1, 3, 7 and 14 in all the patients to check the post-operative nutritional, immunological and liver function status. The mortality, morbidity (wound infections, pancreatic leak, biliary leak, intestinal leak, renal dysfunction, respiratory infections) and lengths of post-operative hospital stay were also recorded. Data was collected in a predesigned data collection sheet, and was compiled, computed and compared between the two groups.

Data are expressed as mean \pm SD and percent. Statistical analysis was performed using the Student $t$ test and Fisher's exact test. The probability differences of .05 or less were considered significant.

\section{RESULTS}

Fourteen out of the 15 patients (93.3\%) tolerated early oral feeding in Group I. The patient that developed abdominal cramps, diarrhea and vomiting after starting formulated food was excluded from the study. There was no difference in age, sex, disease pattern, BMI and associated comorbid conditions between the two groups (Table 1). The clinical presentations were abdominal pain, jaundice,

Table 1. Demographic information of two groups

\begin{tabular}{lccc}
\hline \multicolumn{1}{c}{ Parameter } & $\begin{array}{c}\text { Group I } \\
(\mathrm{n}=14)\end{array}$ & $\begin{array}{c}\text { Group II } \\
(\mathrm{n}=15)\end{array}$ & $p$-value \\
\hline Age (years) & $49.1 \pm 11.6$ & $48.6 \pm 10.5$ & $\mathrm{NS}$ \\
Sex (M:F) & $9: 5$ & $8: 7$ & $\mathrm{NS}$ \\
Disease & & & \\
$\quad$ Pancreas head cancer & $1(7.1)$ & $2(13.3)$ & \\
$\quad$ Ampullary carcinoma & $9(64.3)$ & $10(66.6)$ & $\mathrm{NS}$ \\
$\quad$ Lower bile duct cancer & $4(28.6)$ & $3(20.0)$ & \\
Co-morbidities & & & \\
$\quad \begin{array}{l}\text { Diabetes Mellitus } \\
\text { Hypertension }\end{array}$ & $4(28.6)$ & $3(20.0)$ & \\
$\quad$ Bronchial Asthma & $1(7.1)$ & $1(6.6)$ & \\
Body Mass Index (BMI) & $22.7 \pm 4.3$ & $22.2 \pm 2.1$ & $\mathrm{NS}$ \\
\hline
\end{tabular}

Figure within parentheses indicates in percentage 
itching, anorexia and weight loss with no difference of clinical presentation between the two groups. The serum total bilirubin and alkaline phosphatase levels were higher than normal in both groups. The prothrombin time, INR and serum albumin levels were mildly disarranged in both groups. However, the liver function values did not significantly differ in both groups of patients (Table 2). The amount of blood loss $(440 \pm 19 \mathrm{ml}$ vs $510 \pm 83 \mathrm{ml})$, time required for operation $(4.5 \pm 0.2 \mathrm{~h}$ vs $4.6 \pm 0.7 \mathrm{~h})$ and amount of blood transfusion $(3.5 \pm 2.1 \mathrm{U}$ vs $3.6 \pm 1.8 \mathrm{U})$ were similar between both groups I and II. Most of the patients had a duct to mucosa technique of pancreatojejunal anastomosis $(92.8 \%)$ in group I patients. The Dunkin procedure $(80.0 \%)$ was applied in the group II patients and the difference was significant $(p<0.001)$.

The serum albumin was considered a nutritional indicator and it was checked for two weeks post-operatively to assess both groups from a nutritional point of view. It was found that the albumin level decreased from a preoperative level up to the third POD and it gradually increased from seventh POD onwards in both groups. It was also found that the serum albumin remained in a persistently higher level in group I than group II, even though

Table 2. Preoperative liver functions of two groups

\begin{tabular}{lccc}
\hline \multicolumn{1}{c}{ Parameter } & $\begin{array}{c}\text { Group I } \\
(\mathrm{n}=14)\end{array}$ & $\begin{array}{c}\text { Group II } \\
(\mathrm{n}=15)\end{array}$ & $p$-value \\
\hline Serum bilirubin $(\mathrm{mg} / \mathrm{dl})$ & $5.8 \pm 3.3$ & $6.3 \pm 5.4$ & $\mathrm{NS}$ \\
Alkaline phosphate (IU/L) & $513.6 \pm 175.0$ & $566.4 \pm 435.8$ & $\mathrm{NS}$ \\
Prothrombin time (sec) & $13.8 \pm 1.3$ & $14.2 \pm 1.2$ & $\mathrm{NS}$ \\
INR & $0.95 \pm 0.08$ & $0.93 \pm 0.04$ & $\mathrm{NS}$ \\
Serum albumin $(\mathrm{mg} / \mathrm{dl})$ & $3.2 \pm 0.4$ & $3.2 \pm 0.5$ & $\mathrm{NS}$ \\
\hline
\end{tabular}

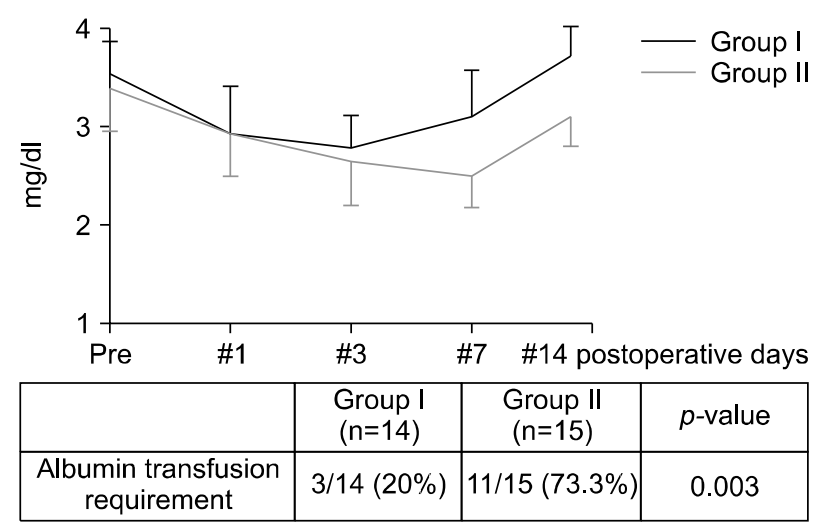

Fig. 1. Changes in serum albumin level between two groups. the values were not significantly different between the two groups (Fig. 1). The post-operative requirement of albumin transfusion were more in group II (70\%) than group I $(20 \%)$, and the differences was statistically significant $(p=0.003)$.

The blood lymphocyte count was considered an immunological indicator. It was checked post-operatively for up to two weeks to assess the immunological status of the patients in both groups. The lymphocyte count decreased in the initial post-operative period up to third POD in both groups. However, the count increased in group I significantly than in group II from the third POD onward (Fig. 2).

The serum total bilirubin and alkaline phosphatase were measured up to two weeks post-operatively for assessing intrahepatic cholestasis in both groups. The total bilirubin and alkaline phosphatase decreased to normal levels within the seventh POD in group I. In contrast, the total bilirubin and alkaline phosphatase still remained higher than the normal levels on the fourteenth POD in group II (Fig. 3).

Wound infections occurred in 10 out of 15 patients $(66.7 \%)$ in the group II patients. In contrast, the wound infection occurred in 2 out of 14 patients (14.2\%) in group I, and the difference was statistically significant $(p=0.003)$. Three patients $(20 \%)$ developed pancreatic leak in group II. In contrast, only one patient (7.1\%) developed a pancreatic leakage, and the difference was not statistically significant. Other complications, renal dysfunction and respiratory infections were similar in both groups. Mortality occurred in patients (13.3\%) in group II, but none in group I. The patient of group I discharged from the hospital had a mean of 13.2 days $( \pm 4.48)$ after surgery. In contrast, group II patients were discharged with a mean of 17.8 days $( \pm 4.80)$, and the difference was statistically

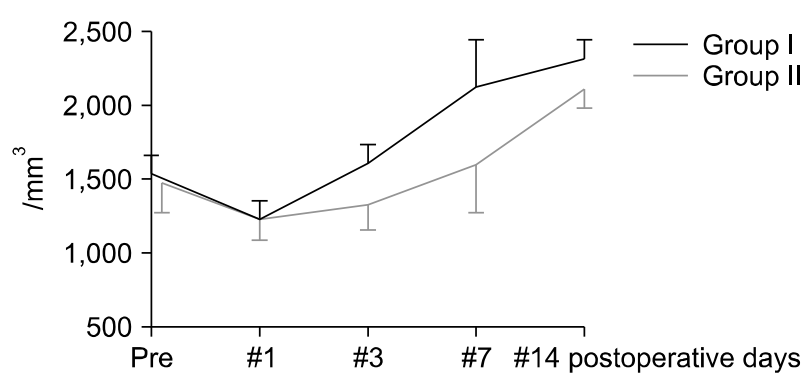

Fig. 2. Changes in blood lymphocyte count between two groups. 
A

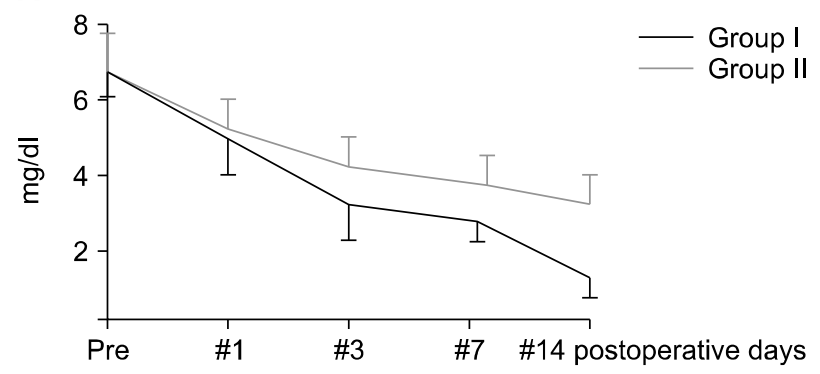

B

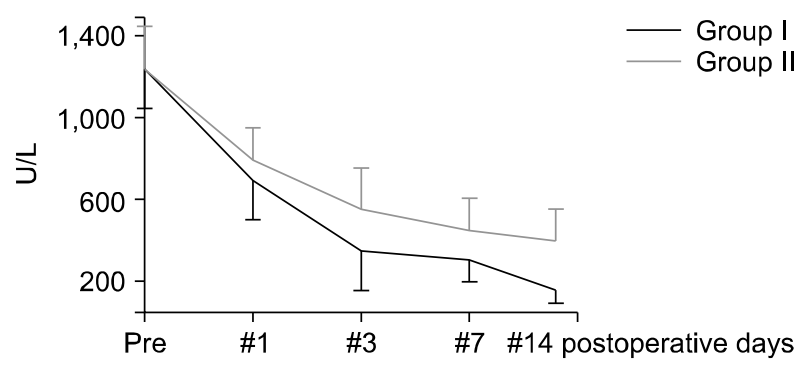

Fig. 3. (A) Changes in serum total bilirubin level between two groups. (B) Changes in serum alkaline phosphate level between two groups.

Table 3. Outcome of after surgery in two groups

\begin{tabular}{lccc}
\hline \multicolumn{1}{c}{ Parameters } & $\begin{array}{c}\text { Group I } \\
(\mathrm{n}=14)\end{array}$ & $\begin{array}{c}\text { Group II } \\
(\mathrm{n}=15)\end{array}$ & $p$-value \\
\hline $\begin{array}{l}\text { Albumin transfusion } \\
\text { requirement }\end{array}$ & $3(20.0)$ & $11(73.3)$ & 0.003 \\
$\begin{array}{l}\text { Morbidity } \\
\text { Wound infection }\end{array}$ & $4(28.5)$ & $10(66.7)$ & 0.003 \\
Wound dehiscence & 0 & $6(40.0)$ & \\
Pancreatic leak & $1(7.1)$ & $2(13.3)$ & \\
Biliary leak & 0 & 0 & \\
Renal dysfunction & $1(7.1)$ & 0 & \\
$\quad$ Respiratory infection & 0 & $1(6.6)$ & \\
Mortality & 0 & 0 & \\
Hospital stay & $13.20 \pm 4.48$ & $17.80 \pm 4.80$ & 0.011 \\
(days after surgery) & & & \\
\hline
\end{tabular}

Figure within parentheses indicates in percentage

significant (Table 3).

\section{DISCUSSION}

The post-operative early total enteral feeding is not always tolerated by the patient after a major surgery. It may be associated with complications, such as diarrhea, abdominal distention and abdominal cramps. ${ }^{10}$ The tube related complications that were noted included tube dislodgement, clogging, intestinal obstruction, infection at the entry site, small bowel necrosis and massive intestinal pneumatosis. ${ }^{11}$ In this study, we started with small volume enteral feeding $(30 \mathrm{ml} / 2 \mathrm{~h}, 10$ feeds from the second day post-operatively). The feeding was increased gradually up to an optimum level within the seventh and eighth POD. We used a nasojejunal feeding tube for placing enteral food in the jejunum instead of a percutaneuos jejunal or gastric feeding tube. This is the reason why more than $90 \%$ patients tolerated the enteral feeding, and no tube re- lated complications were seen in our patients.

In many other studies, ${ }^{12-14}$ the serum albumin, total protein and rapid-turn-over proteins, such as pre-albumin and transferring, were used for assessing the post-operative nutritional parameters. The lymphocyte count and T-cell subpopulation, i.e. CD4/CD8, were used for assessing the post-operative immunological parameters. The serum total bilirubin and alkaline phosphates were used as an assessment of intrahepatic cholestasis. ${ }^{14}$ Similarly, in this study we used the serum albumin, lymphocyte count, bilirubin and alkaline phosphates for assessing post-operative nutritional, immunological and intrahepatic cholestasis. Our observation was that nutritional and immunological status remain higher throughout the whole post-operative period until the discharge in patients where the enteral feeding was started earlier (Group I) than who are not (Group II), even though there is no statistical significant difference. Another important finding was that a significant amount of albumin transfusion was required in group II than in group I patients in order to maintain a postoperative serum albumin level. Post-operative intrahepatic cholestesis was reduced remarkably in the early oral feeding group than delay starting oral feeding group. All these findings can be explained by the experiments done and observed by others. ${ }^{7,10,15}$ It is has been shown that the absence of food in the gut has several metabolic and endocrine consequences on intestinal and liver function. Zhu et al. ${ }^{10}$ reported in an experimental study that the fasted state reduces the secretion of several gastrointestinal hormones such as cholecystokinin, gastrin and peptide YY. These hormones are instrumental in stimulating bile flow and gall bladder contraction, for maintaining intestinal motility. Enteral feeding also stimulates hepatic circulation and ameliorate liver function. Others researchers ${ }^{7,10,15}$ reported 
that enteral feeding improves the immune status, reduces clinical infection, maintains gut structure and function, and can potentially attenuate catabolic stress responses in patients after surgery. The molecular mechanisms of cholestasis have been studied in animal models. ${ }^{16-21}$ Bile flow is mainly impaired due to changes in bile acid transport. The NTCP (mouse), OATP, BSEP (human) and MRP2 (human) are important bile acid receptors of hepatocyte that maintain bile flow from hepatocytes to biliary canaliculi. It has been shown that absence of food in the gut causes lipopolysaccharide (LPS) translocation. This LPS induces Kupffer cells to release pro-inflammatory cytokines (TNF- $\alpha$, IL- $\beta 1$ ), which lead to downregulation of the NTCP, OATP, BSEP and MRP2 receptors in animal and human studies transporters involved in bile flow, coordinated by nuclear receptors and transcription factors. The key transporters are down regulated when food is absent in the gut. Therefore, bacterial translocation in the portal circulation causes intrahepatic cholestasis. Early enteral feeding prevented bacterial translocation in patients of group I, and thus, post-operative serum bilirubin and alkaline phosphatase decreased more rapidly in group I than group II patients. In a study, Hwang et al. ${ }^{22}$ demonstrated the clinical feasibility and nutritional effects of early oral feeding after pancreaticoduodenectomy. They concluded that early enteral feeding reduces mortality, morbidity and the length of hospital stay.

In conclusion, early enteral feeding should be considered after pancreatectomy. This is because it will improve the nutritional status, liver function, post-surgical infection complications. Early oral feeding reduces morbidity and shortens the hospital stay after pancreatoduodenectomy. Since the number of patients in the study was small, the actual effect of early enteral feeding on pancreatoduodenectomy can be studied with the use of more patients in future.

\section{REFERENCES}

1. Pappas S, Krzywda E, McDowell N. Nutrition and pancreaticoduodenectomy. Nutr Clin Pract 2010;25:234-243.

2. Alfargieny R, Bodalal Z, Bendardaf R, El-Fadli M, Langhi S. Nutritional status as a predictive marker for surgical site infection in total joint arthroplasty. Avicenna J Med 2015;5:117-122.

3. Quain AM, Khardori NM. Nutrition in wound care management: a comprehensive overview. Wounds 2015;27:327-335.

4. Phillips B. Reducing gastrointestinal anastomotic leak rates: re- view of challenges and solutions. Open Access Surg 2016;9:5-14.

5. Nagata S, Fukuzawa K, Iwashita Y, Kabashima A, Kinoshita T, Wakasugi $\mathrm{K}$, et al. Comparison of enteral nutrition with combined enteral and parenteral nutrition in post-pancreaticoduodenectomy patients: a pilot study. Nutr J 2009;8:24.

6. Worsh CE, Tatarian T, Singh A, Pucci MJ, Winter JM, Yeo CJ, et al. Total parenteral nutrition in patients following pancreaticoduodenectomy: lessons from 1184 patients. J Surg Res 2017;218:156-161.

7. Baradi H, Walsh RM, Henderson JM, Vogt D, Popovich M. Postoperative jejunal feeding and outcome of pancreaticoduodenectomy. J Gastrointest Surg 2004;8:428-433.

8. Gerritsen A, Besselink MG, Cieslak KP, Vriens MR, Steenhagen E, van Hillegersberg R, et al. Efficacy and complications of nasojejunal, jejunostomy and parenteral feeding after pancreaticoduodenectomy. J Gastrointest Surg 2012;16:1144-1151.

9. Gärtner S, Krüger J, Aghdassi AA, Steveling A, Simon P, Lerch $\mathrm{MM}$, et al. Nutrition in pancreatic cancer: a review. Gastrointest Tumors 2016;2:195-202.

10. Zhu XH, Wu YF, Qiu YD, Jiang CP, Ding YT. Effect of early enteral combined with parenteral nutrition in patients undergoing pancreaticoduodenectomy. World J Gastroenterol 2013;19:58895896.

11. Akbarshahi H, Andersson B, Nordén M, Andersson R. Perioperative nutrition in elective gastrointestinal surgery--potential for improvement? Dig Surg 2008;25:165-174.

12. Liao Q, Zhao YP, Wang WB, Dai MH, Hu Y, Liu ZW, et al. [Perioperative nutrition support of the patients with pancreatic head cancer]. Acta Acad Med Sin 2005;27:579-582. Chinese.

13. Nagata S, Fukuzawa K, Iwashita Y, Kabashima A, Kinoshita T, Wakasugi $\mathrm{K}$, et al. Comparison of enteral nutrition with combined enteral and parenteral nutrition in post-pancreaticoduodenectomy patients: a pilot study. Nutr J 2009;8:24.

14. Siddique A, Kowdley KV. Approach to a patient with elevated serum alkaline phosphatase. Clin Liver Dis 2012;16:199-229.

15. Gerritsen A, Besselink MG, Cieslak KP, Vriens MR, Steenhagen E, van Hillegersberg R, et al. Efficacy and complications of nasojejunal, jejunostomy and parenteral feeding after pancreaticoduodenectomy. J Gastrointest Surg 2012;16:1144-1151.

16. Elferink MG, Olinga P, Draaisma AL, Merema MT, Faber KN, Slooff MJ, et al. LPS-induced downregulation of MRP2 and BSEP in human liver is due to a posttranscriptional process. Am J Physiol Gastrointest Liver Physiol 2004;287:G1008-G1016.

17. Green RM, Beier D, Gollan JL. Regulation of hepatocyte bile salt transporters by endotoxin and inflammatory cytokines in rodents. Gastroenterology 1996;111:193-198.

18. Geier A, Dietrich CG, Voigt S, Kim SK, Gerloff T, KullakUblick GA, et al. Effects of proinflammatory cytokines on rat organic anion transporters during toxic liver injury and cholestasis. Hepatology 2003;38:345-354.

19. Cherrington NJ, Slitt AL, Li N, Klaassen CD. Lipopolysaccharide-mediated regulation of hepatic transporter mRNA levels in rats. Drug Metab Dispos 2004;32:734-741.

20. Denson LA, Auld KL, Schiek DS, McClure MH, Mangelsdorf DJ, Karpen SJ. Interleukin-1beta suppresses retinoid transactivation of two hepatic transporter genes involved in bile formation. J Biol Chem 2000;275:8835-8843.

21. Kubitz R, Wettstein M, Warskulat U, Häussinger D. Regulation of the multidrug resistance protein 2 in the rat liver by lipopolysaccharide and dexamethasone. Gastroenterology 1999;116: 401-410.

22. Hwang SE, Jung MJ, Cho BH, Yu HC. Clinical feasibility and nutritional effects of early oral feeding after pancreaticoduodenectomy. Korean J Hepatobiliary Pancreat Surg 2014;18:84-89. 